\title{
Transport of Antarctic bottom water through the Kane Gap, tropical NE Atlantic Ocean
}

\author{
E. G. Morozov ${ }^{1}$, R. Y. Tarakanov ${ }^{1}$, and H. van Haren ${ }^{2}$ \\ ${ }^{1}$ Shirshov Institute of Oceanology, Russian Academy of Sciences, Nakhimovsky pr. 36, Moscow, 117997, Russia \\ ${ }^{2}$ Royal Netherlands Institute for Sea Research (NIOZ), P.O. Box 59, 1790 AB, Den Burg, the Netherlands
}

Correspondence to: E. G. Morozov (egmorozov@mail.ru)

Received: 18 January 2013 - Published in Ocean Sci. Discuss.: 11 March 2013

Revised: 8 August 2013 - Accepted: 9 August 2013 - Published: 23 September 2013

\begin{abstract}
We study low-frequency properties of the Antarctic Bottom Water (AABW) flow through the Kane Gap $\left(9^{\circ} \mathrm{N}\right)$ in the Atlantic Ocean. The measurements in the Kane Gap include five visits with CTD (Conductivity-TemperatureDepth) sections in 2009-2012 and a year-long record of currents on a mooring using three AquaDopp current meters. We found an alternating regime of flow, which changes direction several times during a year. The seasonal signal seems to dominate. The maximum daily average values of southerly velocities reach $0.20 \mathrm{~m} \mathrm{~s}^{-1}$, while the greatest north-northwesterly velocity is as high as $0.15 \mathrm{~m} \mathrm{~s}^{-1}$. The velocity and transport at the bottom are aligned along the slope of a local hill near the southwestern side of the gap. The distribution of velocity directions at the upper boundary of AABW is wider. The transport of AABW $\left(\Theta<1.9^{\circ} \mathrm{C}\right)$ based on the mooring and LADCP (Lowered Acoustic Doppler Current Profiler) data varies approximately within $\pm 0.35 \mathrm{~Sv}$ in the northern and southern directions. The annual mean AABW transport through the Kane Gap is almost zero.
\end{abstract}

\section{Introduction}

Cold bottom waters over the major part of the Atlantic Ocean are of the Antarctic origin. They are formed mainly in the Weddell Sea near the Antarctic slope as a result of cascading and mixing of cold and dense Antarctic Shelf Water through the layer of warmer and more saline circumpolar waters. The pathways of northward propagation of the formed Antarctic bottom waters between the deep basins of the Atlantic Ocean are confined to the depressions in the bottom topography. These waters propagate from the Weddell Sea to the Sco- tia Sea through several passages in the South Orkney Ridge. Then, they penetrate to the Argentine Basin while merging with the Antarctic Bottom Water transported from the Weddell Sea through the South Sandwich Trench and with the densest layers of circumpolar waters. We follow the definition of these waters given in Wüst (1936) and name Antarctic Bottom Water (AABW) all the bottom waters propagating in the Atlantic Ocean from Antarctica to the north. We note that in different regions of the Atlantic Ocean the upper boundary can be associated with different values of potential temperature $(\Theta)$ from 1.8 to $2.3^{\circ} \mathrm{C}$ and density. This information is given in some tables in Morozov et al. (2010a). The transport of AABW to the Argentine Basin is estimated at $8 \mathrm{~Sv}$ (Hogg, 2001). The waters are later transported to the Brazil Basin along three pathways: the Vema Channel, the Hunter Channel, and over the Santa Catarina Plateau, which is frequently called in the literature the Santos Plateau (Hogg, et al., 1999). The Vema Channel allows for the major part of the AABW transport to the north, which is estimated at 3-4 Sv (Morozov et al., 2010a). Figure 1 shows a scheme of AABW propagation in the bottom layer (Morozov et al., 2010a).

After propagating to the north of the Brazil Basin, part of AABW is transported to the eastern Atlantic Ocean through the Romanche and Chain fracture zones (FZ). Another part flows to the Equatorial Channel and Guyana Basin (Hall et al., 1997) and later splits, propagating to the east through the Vema Fracture Zone and to the northwest to the North American Basin (Morozov et al., 2010a).

The Vema, Romanche, and Chain transform fracture zones are the main pathways for bottom water propagation to the eastern Atlantic Basin. Before the bottom water enters the Romanche Fracture Zone its temperature is $0.674{ }^{\circ} \mathrm{C}$; the 


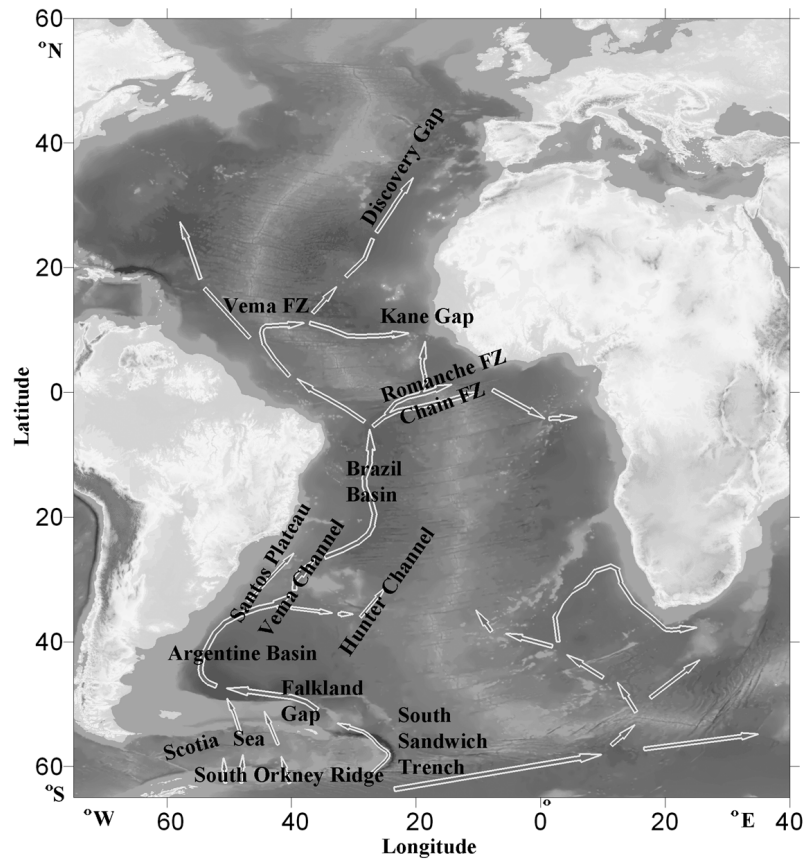

Fig. 1. Scheme of AABW propagation in the Atlantic Ocean.

coldest temperature at the entrance to the Chain Fracture Zone is $0.682^{\circ} \mathrm{C}$ (Mercier and Morin, 1997). The recent measurements in 2011 recorded a temperature of $0.508^{\circ} \mathrm{C}$ before the Romanche Fracture Zone and $0.648^{\circ} \mathrm{C}$ in the fracture at $22^{\circ} 20^{\prime} \mathrm{W}$ (Morozov et al., 2012; Tarakanov et al., 2013). The potential temperature at the entrance to the Vema Fracture Zone is $\Theta=1.33^{\circ} \mathrm{C}$ (Mantyla and Reid, 1983). The lowest potential temperatures after the exit from the fracture zones are $\Theta=1.66^{\circ} \mathrm{C}$ (Romanche) and $\Theta=1.69^{\circ} \mathrm{C}$ (Vema) (Mantyla and Reid, 1983). The values are very similar due to stronger mixing in the Romanche FZ.

Measurements of velocities using current meters in the Romanche and Chain fracture zones revealed comparable easterly transports of Antarctic waters of 0.66 and $0.56 \mathrm{~Sv}$, respectively (Mercier and Speer, 1998). These results are close to the independent estimates of bottom water transport through the Romanche Fracture Zone of $0.5 \mathrm{~Sv}$ obtained using LADCP (Lowered Acoustic Doppler Current Profiler) current measurements in 2005 (Morozov et al., 2010a). In addition, the results of measurements in 2006 (Morozov et al., 2010a) recorded a transport of $0.4 \mathrm{~Sv}$ over the main sill of the Vema Fracture Zone $\left(11^{\circ} \mathrm{N}\right)$. These measurements are near the lower limit of the published estimates. The values were calculated for the transport below the $1.9^{\circ} \mathrm{C}$ isotherm. Other researchers report higher values: Fischer et al. (1996) measured a transport of $1.8-2 \mathrm{~Sv}$ below $2{ }^{\circ} \mathrm{C}$, McCartney et al. (1991) reported 1.3-3.0 Sv, and Rhein et al. (1998) 1.1 Sv. More information on the transport in the channels is given in our book (Morozov et al., 2010a).

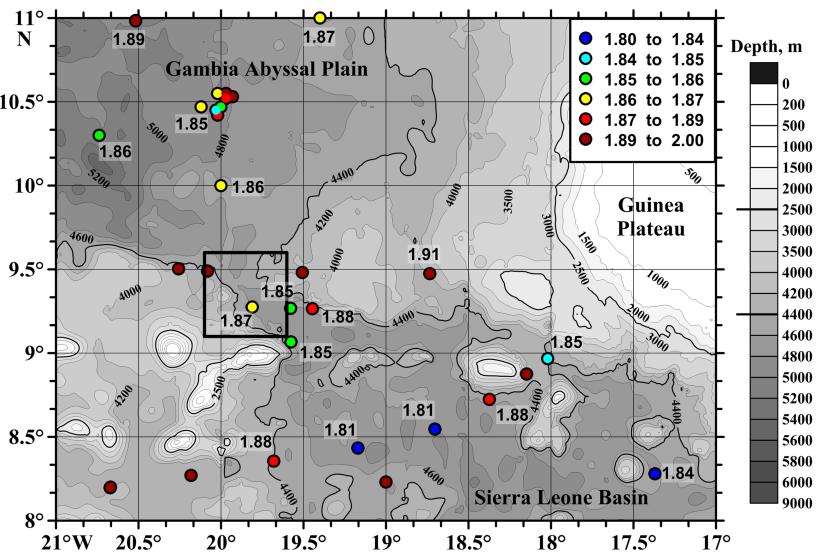

Fig. 2. Bathymetry of the Kane Gap region with observations of near-bottom potential temperature $\left({ }^{\circ} \mathrm{C}\right)$ according to the WOD09 database. Historical stations are shown with dots of different color depending on the temperature (see notations in the inset; our study region is shown with a black square). Updated and adopted with modifications from Morozov et al. (2010b).

Mantyla and Reid (1983) conclude that the waters that propagate through the Romanche Fracture Zone influence only the regions of the Guinea, Sierra Leone, and partly Angola basins, whereas the waters that flow through the Vema Fracture Zone influence the Gambia Abyssal Plain, the Canary, and possibly the Iberian basins (van Aken, 2000). They actually fill the entire bottom layer in the northeastern Atlantic Ocean. A scheme of AABW propagation in the Gambia Abyssal Plain was suggested in McCartney et al. (1991). This scheme was illustrated in Morozov et al. (2010a) based on the recent measurements of potential temperature near the bottom.

Antarctic Bottom Water propagates to the eastern Atlantic Ocean through two main passages in the Mid-Atlantic Ridge: the Vema Fracture Zone (at $11^{\circ} \mathrm{N}$ ) and Romanche and Chain fracture zones (at the Equator) and then reaches the Kane Gap west of Guinea. It is seen in Fig. 2 that the minimum ever measured potential temperature by CTD (ConductivityTemperature-Depth) casts at the bottom, close to the Kane Gap (at depths of 4600-4650 m that correspond to the depth of the sill), is $1.85^{\circ} \mathrm{C}$. This indicates that bottom waters with temperatures lower than this value transported to the region of the Kane Gap from the two sources are separated by the sill in the gap, while warmer mixed waters can flow over the sill. Thus, only the warmest part of Antarctic Bottom Water $\left(2.00^{\circ} \mathrm{C}>\Theta>1.85^{\circ} \mathrm{C}\right)$ can exchange over the sill of the Kane Gap. We note that Fig. 2. was constructed on the basis of water sample data and CTD profilers from the WOD09 database (WOD09, 2009), supplemented with the results of Hobart et al. (1975).

In 2009-2012, the scientists from the Shirshov Institute of Oceanology significantly supplemented the available data set of temperature and salinity in the Kane Gap. In May 2009 


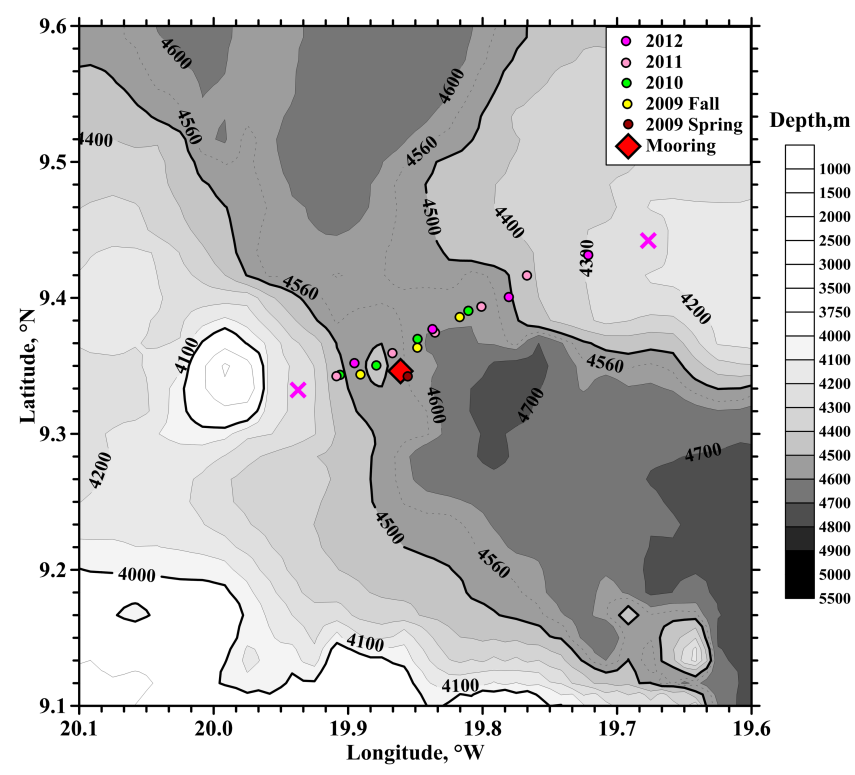

Fig. 3. Bottom topography in the Kane Gap region based on Smith and Sandwell (1997) and echo-sounding measurements during cruises. Locations of CTD and LADCP stations in 2009-2012 and the mooring (diamond) are shown. The crosses indicate the beginning and end of the bathymetry section in 2012 .

we, for the first time, carried out the measurements of currents. Before, even the direction of bottom water flow through this passage was not clear. The only source of information about the currents was based on the oriented underwater photos. According to these observations the current was directed to the northwest, from the Sierra Leone Basin to the Gambia Abyssal Plain (Hobart et al., 1975).

\section{The data}

In order to understand the flow of bottom water in the Kane Gap we performed a series of CTD casts and longterm mooring measurements at the sill of the gap $\left(9^{\circ} 20^{\prime} \mathrm{N}\right.$, $19^{\circ} 51^{\prime} \mathrm{W}$, approximate depth $4560 \mathrm{~m}$ ). This program started in 2009 and has continued until now. During the period 2009-2012, we carried out five series of CTD (SBE-19) casts combined with LADCP (RDI WHS $300 \mathrm{kHz}$ ) measurements (Fig. 3, Table 1).

In May 2009, during a Russian expedition onboard the R/V Akademik Ioffe, cruise 27 (AI-27), measurements of currents were performed for the first time near the main sill of the Kane Gap (Fig. 3) using a LADCP combined with CTD profiling (Morozov et al., 2010b); only one station was occupied. In October 2009 (cruise AI-29), we continued the measurements in the Kane Gap (Fig. 3). A CTD section of three stations was occupied combined with LADCP profiling. In October 2010 (cruise AI-32), another CTD section with LADCP measurements at four stations was occupied in

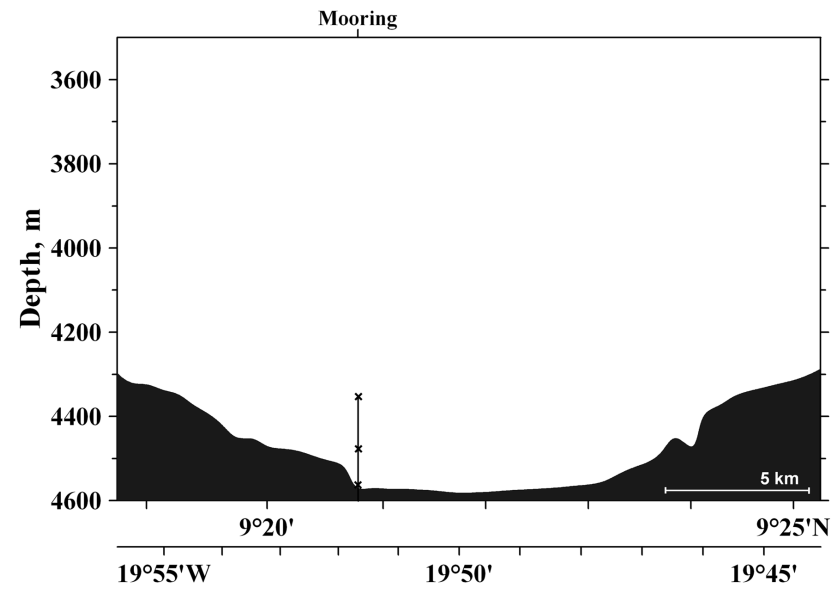

Fig. 4. A scheme of the mooring location over the topographic section across the Kane Gap. Crosses indicate the depths of current meters. The horizontal scale is shown in the bottom right corner.

the Kane Gap (Fig. 3). In October 2011, during an expedition onboard the R/V Akademik Sergey Vavilov (cruise ASV34) a CTD section with LADCP measurements at five stations was conducted, and in October 2012 (cruise ASV-36), a CTD section with LADCP measurements at four stations was carried out. In October 2012, we also carried out a detailed echo sounder survey in the region of the Kane Gap along the line of the section.

In October 2010, we deployed a mooring with three Nortek AquaDopp acoustic current meters (Figs. 3, 4) at $9^{\circ} 20.7^{\prime} \mathrm{N}, 19^{\circ} 51.7^{\prime} \mathrm{W}$. It was recovered in October 2011. The mooring operation was carried out jointly with the Royal Netherlands Institute for Sea Research (NIOZ). The instruments measured currents at $1.5 \mathrm{~m}$ from the head at the operation frequency equal to $2 \mathrm{MHz}$. The instruments were fixed at 4352, 4477, and $4562 \mathrm{~m}$. The deepest instrument was $7 \mathrm{~m}$ above the bottom. The sampling period was $600 \mathrm{~s}$ (10 min). The sections in 2010 and 2011 were occupied immediately before and after the deployment and recovery of the mooring.

All instruments used in the cruises were calibrated before each cruise. The accuracies of SBE- 19 sensors are $0.003^{\circ} \mathrm{C}$, $0.0005 \mathrm{Sm}^{-1}$, and $1 \mathrm{~dB}$. The accuracy of LADCP current measurements in the bottom layer if the bottom track was available is $0.01 \mathrm{~m} \mathrm{~s}^{-1}$ and $5^{\circ}$ of direction. The raw CTD and LADCP data were processed using the standard software LADCP Processing, version IX.7, which is described in Visbeck (2002).

Of all mentioned data, only the measurements in May 2009 were previously published (Morozov et al., 2010a, b). The publications in 2011-2012 are cruise reports only with the information of the activities in the cruises without data analysis. In this paper we focus our attention on the velocities and transports measured using LADCP and moored instruments. 
Table 1. CTD stations at different cruises of the R/Vs Akademik Ioffe (AI) and Akademik Sergey Vavilov (ASV).

\begin{tabular}{llll}
\hline Date & Station, cruise & Coordinates & $\begin{array}{l}\text { Lowest measurement/ } \\
\text { ocean depth }(\mathrm{m})\end{array}$ \\
\hline 01.052009 & $2084 \mathrm{AI}-27$ & $09^{\circ} 20.6^{\prime} \mathrm{N}, 19^{\circ} 51.3^{\prime} \mathrm{W}$ & $4553 / 4565$ \\
30.102009 & $2159 \mathrm{AI}-29$ & $09^{\circ} 23.4^{\prime} \mathrm{N}, 19^{\circ} 49.1^{\prime} \mathrm{W}$ & $4567 / 4579$ \\
30.102009 & $2160 \mathrm{AI}-29$ & $09^{\circ} 21.9^{\prime} \mathrm{N}, 19^{\circ} 50.9^{\prime} \mathrm{W}$ & $4566 / 4572$ \\
31.102009 & $2161 \mathrm{AI}-29$ & $09^{\circ} 20.8^{\prime} \mathrm{N}, 19^{\circ} 53.5^{\prime} \mathrm{W}$ & $4536 / 4549$ \\
20.102010 & $2423 \mathrm{AI}-32$ & $09^{\circ} 20.6^{\prime} \mathrm{N}, 19^{\circ} 54.3^{\prime} \mathrm{W}$ & $4502 / 4512$ \\
20.102010 & $2424 \mathrm{AI}-32$ & $09^{\circ} 21.0^{\prime} \mathrm{N}, 19^{\circ} 52.7^{\prime} \mathrm{W}$ & $4444 / 4454$ \\
21.102010 & $2425 \mathrm{AI}-32$ & $09^{\circ} 22.2^{\prime} \mathrm{N}, 19^{\circ} 50.9^{\prime} \mathrm{W}$ & $4540 / 4550$ \\
21.102010 & $2426 \mathrm{AI}-32$ & $09^{\circ} 23.4^{\prime} \mathrm{N}, 19^{\circ} 48.6^{\prime} \mathrm{W}$ & $4545 / 4555$ \\
18.102011 & $2461 \mathrm{ASV}-34$ & $09^{\circ} 25.0^{\prime} \mathrm{N}, 19^{\circ} 42.5^{\prime} \mathrm{W}$ & $4387 / 4397$ \\
18.102011 & $2462 \mathrm{ASV}-34$ & $09^{\circ} 23.6^{\prime} \mathrm{N}, 19^{\circ} 48.1^{\prime} \mathrm{W}$ & $4549 / 4559$ \\
19.102011 & $2463 \mathrm{ASV}-34$ & $09^{\circ} 22.5^{\prime} \mathrm{N}, 19^{\circ} 50.1^{\prime} \mathrm{W}$ & $4566 / 4576$ \\
19.102011 & $2464 \mathrm{ASV}-34$ & $09^{\circ} 21.6^{\prime} \mathrm{N}, 19^{\circ} 52.0^{\prime} \mathrm{W}$ & $4535 / 4545$ \\
19.102011 & $2465 \mathrm{ASV}-34$ & $09^{\circ} 20.5^{\prime} \mathrm{N}, 19^{\circ} 54.5^{\prime} \mathrm{W}$ & $4549 / 4506$ \\
24.102012 & $2474 \mathrm{ASV}-36$ & $09^{\circ} 25.3^{\prime} \mathrm{N}, 19^{\circ} 44.0^{\prime} \mathrm{W}$ & $4284 / 4292$ \\
24.102012 & $2476 \mathrm{ASV}-36$ & $09^{\circ} 23.4^{\prime} \mathrm{N}, 19^{\circ} 47.6^{\prime} \mathrm{W}$ & $4543 / 4551$ \\
24.102012 & $2477 \mathrm{ASV}-36$ & $09^{\circ} 22.0^{\prime} \mathrm{N}, 19^{\circ} 51.0^{\prime} \mathrm{W}$ & $4558 / 4566$ \\
24.102012 & $2478 \mathrm{ASV}-36$ & $09^{\circ} 20.5^{\prime} \mathrm{N}, 19^{\circ} 54.5^{\prime} \mathrm{W}$ & $4498 / 4506$ \\
\hline
\end{tabular}

\section{Data analysis}

\subsection{Bottom topography}

The echo sounder survey in October of 2012 revealed a local hill at the southwestern slope of the Kane Gap. The further analysis demonstrated significant influence of this hill on the direction and structure of the bottom currents in the entire section and at the location of the mooring. The bathymetry measured in 2012 was taken into account when we constructed a chart of the bottom topography (Fig. 3). It was also used for all the sections occupied across the Kane Gap (Figs. 5-8). We used the digital bottom topography of the ocean (Smith and Sandwell, 1997) and recent changes available in the internet as the basis for this chart (http: //topex.ucsd.edu/cgi-bin/get_data.cgi). The differences in the bottom topography in the sections are related to slightly different lines of sections in each year.

\subsection{Sections}

The series of five measurements in 2009-2012 allowed us to analyze the evolution of the near-bottom thermohaline structure and velocity in the Kane Gap. The temperature profile in May 2009 is shown in Fig. 5 and four temperature, salinity, and potential density $\sigma_{4}$ sections in 2009-2012 are shown in Figs. 6 and 7. The distributions of the velocity component in the abyssal layer normal to the sections are shown in Fig. 8a-d. Figure 9 shows $\Theta-$ (salinity) curves for the abyssal layer of these sections.

As seen from the distributions of potential temperature over sections (Fig. 2) and bottom topography charts (Figs. 2, 3 ), the abyssal channel of the Kane Gap oriented from south-

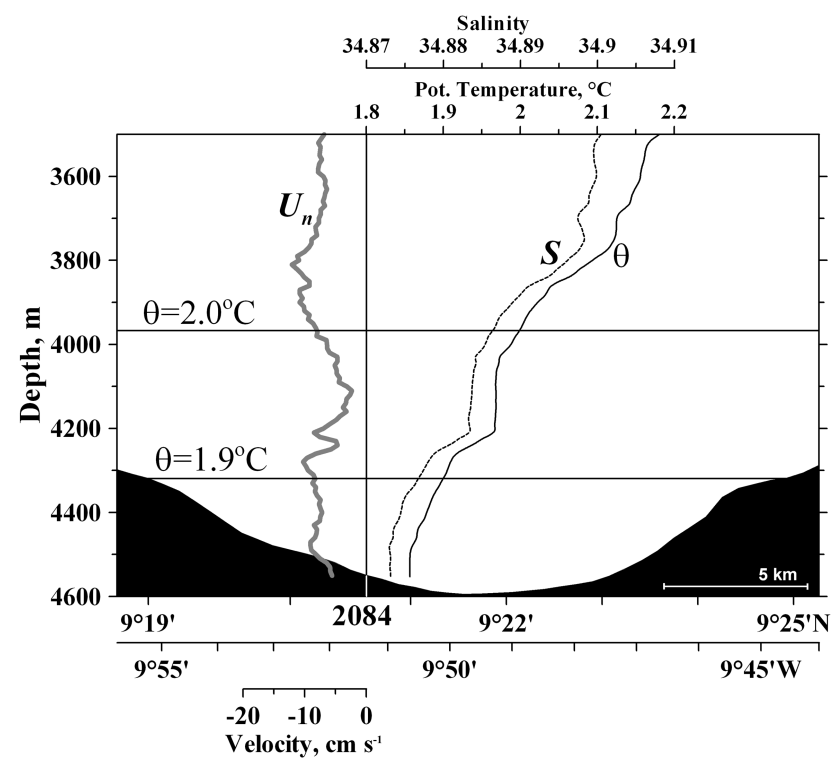

Fig. 5. Profiles of potential temperature $\left({ }^{\circ} \mathrm{C}\right)$, salinity $(S)$, and normal-to-section velocity component $\left(\mathrm{cm} \mathrm{s}^{-1}\right)$ measured in May 2009 at station AI 2084 over the sill of the Kane Gap. Positive velocities of the flow are directed to the northwest. The horizontal scale is shown in the bottom right corner. The hill in the bottom topography shown in Figs. 6-7 is located to the northwest of the line shown here.

east to northwest is a narrow passage only for the coldest part of $\mathrm{AABW}$ with potential temperature below approximately $1.9^{\circ} \mathrm{C}$. The warmer waters propagate through a significantly wider section. This fact does not allow us to use the measurements in 2009-2012 to study in detail the properties 

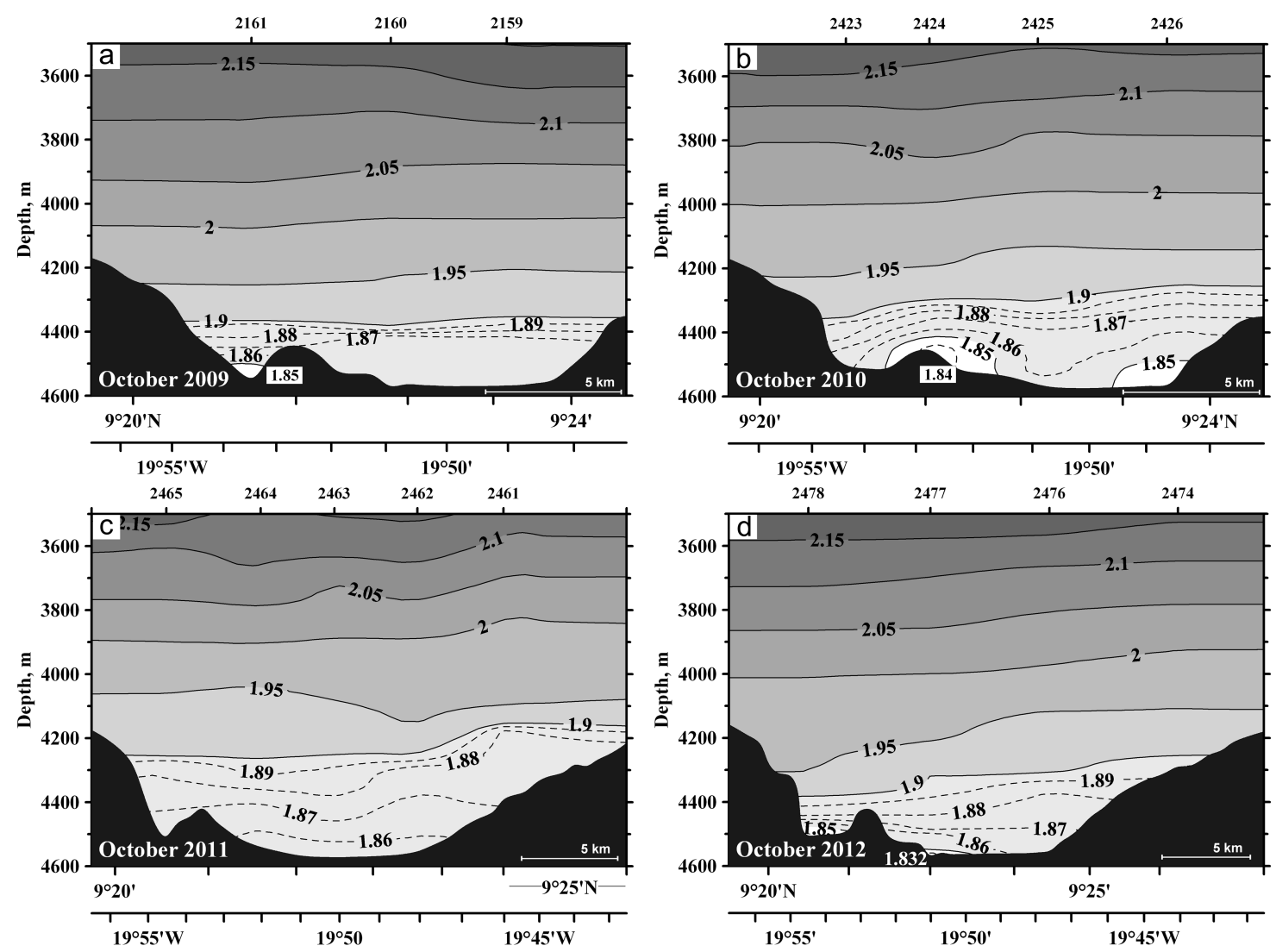

Fig. 6. Sections of potential temperature $\left({ }^{\circ} \mathrm{C}\right.$ ), across the Kane Gap in October 2009 (a), October 2010 (b), October 2011 (c), and October 2012 (d). Numbers of stations are shown above and coordinates are below. The horizontal scale is shown in the bottom right corner. Figure 6a is adopted with modifications from Morozov et al. (2010a).

and structure of water exchange (and neither calculate the transports) in the Kane Gap in the classical understanding of AABW (below the $2{ }^{\circ} \mathrm{C}$ isotherm). Therefore, in this study we shall consider only the layer of cold waters with $\Theta<1.9^{\circ} \mathrm{C}$.

During the first visit to the Kane Gap in May 2009, when only one CTD cast with an LADCP instrument was carried out near the main sill of the Gap (Fig. 5), we unexpectedly revealed a southeasterly abyssal current from the Gambia Abyssal Plain to the Sierra Leone Basin with a sufficient velocity of about $10 \mathrm{~cm} \mathrm{~s}^{-1}$. The potential temperature at the bottom was $1.850^{\circ} \mathrm{C}$.

In October 2009, 2010, and 2012, almost unidirectional (in the general direction to the northwest) currents with velocities up to $10 \mathrm{~cm} \mathrm{~s}^{-1}$ in $2009,13 \mathrm{~cm} \mathrm{~s}^{-1}$ in 2010 , and $8 \mathrm{~cm} \mathrm{~s}^{-1}$ in 2012 were recorded during three of the four sections in the AABW layer (Fig. 8a, b, d). The cores of the current were observed in different places of the section approximately $200 \mathrm{~m}$ over the bottom. In October 2009, the core of the current was located close to the northeastern slope of the Kane Gap; in 2010 and 2012 it was found near the local hill at the southwestern slope. In addition, in 2009 and 2010, we found additional weaker cores of the currents at the slopes oppo- site to the locations of the main cores. In October 2011, we measured very weak differently oriented (southeasterly and northwesterly) currents (in the central part of the gap) whose velocities reached only $5 \mathrm{~cm} \mathrm{~s}^{-1}$ near the bottom (Fig. 8c).

It is seen in Fig. 7 that in all four sections, the densest water was displaced either to the southwestern slope of the Kane Gap or to the local hill near this slope. In October 2010, we recorded one more core of dense water near the northeastern slope (Fig. 7b). We also note elevation of isopycnals detected in all years of measurements over the northeastern slope of the channel for the water layer warmer than $\Theta=1.9^{\circ} \mathrm{C}$. In three of the four sections, excluding October 2010, we observed horizontal thermohaline inhomogeneity in the AABW layer: the colder and lower saline (along the isopycnals) water was located close to the northeastern slope of the Kane Gap (Figs. 6, 7, 9). The maximum differences in salinity along isopycnals reached 0.003 . In addition, the existence of different intrusions of more and less saline water types was recorded, for example near the bottom at station 2463 (Fig. 9c). One can also see such intrusions at stations 2474, 2476 of the section in 2012 (Fig. 9d). In October 2009 we observed a temperature inversion, which was not density compensated (a loop in the bottom layer at 

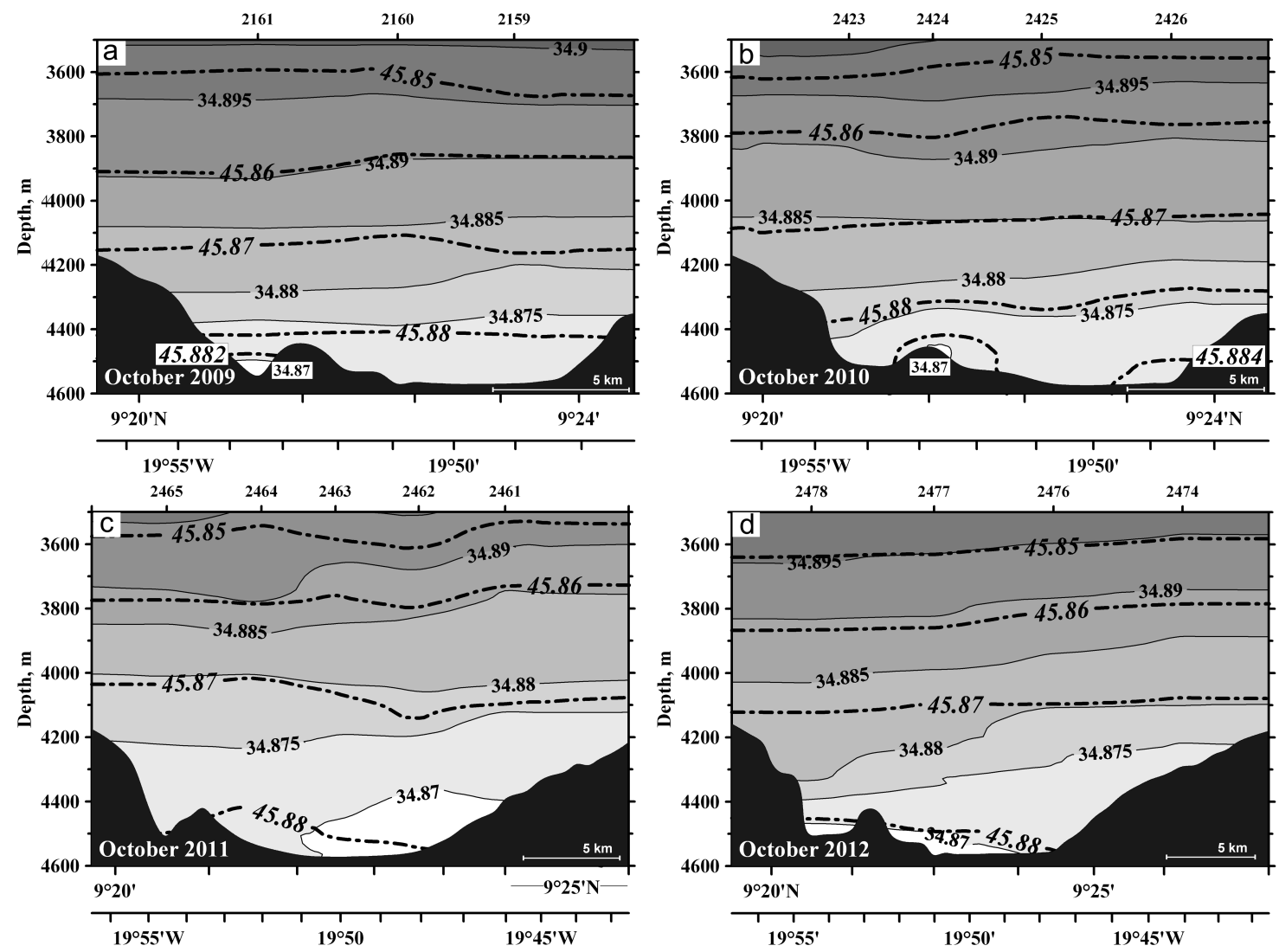

Fig. 7. Sections of salinity, and potential density $\sigma_{4}$ across the Kane Gap in October 2009 (a), October 2010 (b), October 2011 (c), and October 2012 (d). Contour lines of potential density are shown with thick dash-and-dot lines. Numbers of stations are shown above and coordinates are below. The horizontal scale is shown in the bottom right corner. Figure 7a is adopted with modifications from Morozov et al. (2010b).

station 2160 in Fig. 9a). We also indicate minimum potential temperatures measured during the sections in different years: $1.846^{\circ} \mathrm{C}$ in $2009,1.836^{\circ} \mathrm{C}$ in $2010,1.855^{\circ} \mathrm{C}$ in 2011 , and $1.832^{\circ} \mathrm{C}$ in 2012 .

The estimates of transports in the layer $\Theta<1.9^{\circ} \mathrm{C}$ were $0.27 \mathrm{~Sv}$ (to the southeast) in May 2009; 0.11, 0.19, and $0.12 \mathrm{~Sv}$ October of 2009, 2010, and 2012, respectively. In October 2011, the transport estimates in two directions were $0.03 \mathrm{~Sv}$ to the northwest and $0.05 \mathrm{~Sv}$ to the southeast, which jointly gave an almost zero transport of $0.02 \mathrm{~Sv}$ to the southeast. The transport was estimated by interpolating the LADCP velocities onto a grid over the section across the channel using $10 \mathrm{~m}$ layers. The transport estimates through the Kane Gap, even when the transport was the highest, are almost two times smaller than the transport of bottom waters through the Vema Fracture Zone, the source of bottom waters in the northeastern Atlantic Ocean.

In this research we used the data of only one mooring. We estimate the accuracy of calculating the transport based only on one station. With this in mind we calculated the transport based on the data of sections using only one LADCP profile with extreme profiles of velocity. The obtained intervals of transports were $0.06-0.20 \mathrm{~Sv}$ in October 2009, 0.03-0.22 Sv in $2010,-0.15-0.08 \mathrm{~Sv}$ in 2011 , and $0.03-0.19 \mathrm{~Sv}$ in 2012 . Thus, the estimate of transport based on one station fluctuates approximately within $\pm 0.1 \mathrm{~Sv}$ relative to the calculations based on the whole set of data along the section. The bottom topography is another factor influencing the estimate of transport. For example, the previously published transport of May 2009 (0.16 Sv) (Morozov et al., 2010b) is almost 1.5 times smaller than the estimate of $0.27 \mathrm{~Sv}$, owing only to the new data that appeared in the digital bottom topography database on the Internet (http://topex.ucsd.edu/cgi-bin/ get_data.cgi) and also to the measurements during our echo sounder survey in 2012.

\subsection{Mooring}

In May and October of 2009, we found oppositely directed flows in the Kane Gap. This fact incited us to carry out longterm measurements of currents and temperature in the Kane Gap. We planned to deploy a mooring for a long period in order to investigate the time variation of the flow. The mooring with three current meters started to operate in the bottom layer in October 2010. 

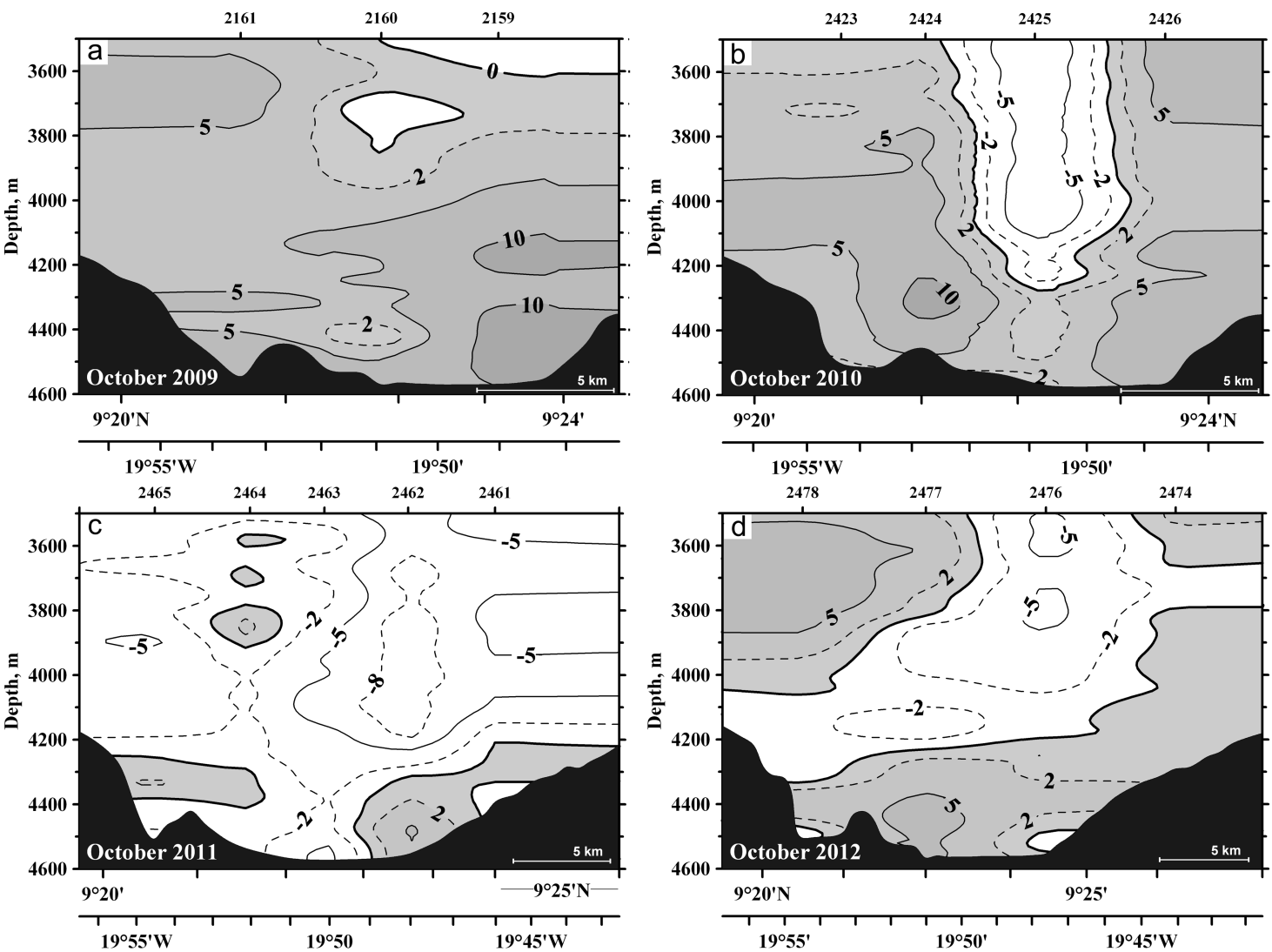

Fig. 8. Sections of velocity (normal to the section, positive to the northwest) ( $\mathrm{cm} \mathrm{s}^{-1}$ ) across the Kane Gap in October 2009 (a), October 2010 (b), October 2011 (c), and October 2012 (d). Numbers of stations are shown above and coordinates are below. The horizontal scale is shown in the bottom right corner. Figure 8a is adopted with modifications from Morozov et al. (2010b).

Figure 10 shows the transport rose for all three current meters. The rose (similar to the wind rose graph) was calculated in two steps. In the first step we performed summing of all velocity measurements in each of the $5^{\circ}$ sectors. In the second step, the transport estimates in each of the sectors were normalized by the total transport over the $360^{\circ}$ circle and related to the sector angle in degrees. In our case, the transport rose almost repeats the rose of currents, i.e., the distribution of currents by directions. However, since the transport rose takes into account the intensity of the current, we present only the transport rose here.

It is seen in Fig. 10 that the currents at depths of 4562 and $4477 \mathrm{~m}$ (at the lower and middle levels) have a bimodal structure. There are only two directions of transport. The transport at $4562 \mathrm{~m}$ is directed to the south with a slight deviation to the east or to the north-northwest. The transport at $4477 \mathrm{~m}$ changed slightly. The general directions of the flow are to the south or to the north with a slight deviation to the east. The mean velocities in the direction of the maximum transport were $14 \mathrm{~cm} \mathrm{~s}^{-1}$ to the south and $11 \mathrm{~cm} \mathrm{~s}^{-1}$ to the north at the lower level; 17 and $12 \mathrm{~cm} \mathrm{~s}^{-1}$, respectively at the middle level. The maximum daily average velocities were $20 \mathrm{~cm} \mathrm{~s}^{-1}$ to the south and $15 \mathrm{~cm} \mathrm{~s}^{-1}$ to the north at the lower level and 22 and $17 \mathrm{~cm} \mathrm{~s}^{-1}$, respectively at the middle level. These directions of the currents do not correspond to the general northwest-southeast orientation of the Kane Gap channel. We think that it is presumably caused by the local orientation of the underwater hill slope, near which the mooring was deployed.

Four directions are distinguished at a level of $4352 \mathrm{~m}$. Two of them approximately correspond to the directions of the currents at the lower levels. The mean velocities in these directions were $8 \mathrm{~cm} \mathrm{~s}^{-1}$ to the south and $10 \mathrm{~cm} \mathrm{~s}^{-1}$ to the north; the maximum daily average values were $9 \mathrm{~cm} \mathrm{~s}^{-1}$ to the south and $14 \mathrm{~cm} \mathrm{~s}^{-1}$ to the north. The two other directions are east-southeast and northwest. The main transport at this level corresponds to these pairs of directions unlike the transport at the middle and lower levels. The mean velocities in both directions were $14 \mathrm{~cm} \mathrm{~s}^{-1}$ to the southwest and $9 \mathrm{~cm} \mathrm{~s}^{-1}$ to the northeast. These directions are actually transverse relative to the orientation of the Kane Gap channel. This fact indicates that the currents at $4352 \mathrm{~m}$ adjust not to the channel topography but to other constraints.

A peculiarity that can be seen in Fig. 10 is the asymmetry of transport directions at the two lower levels. This asymmetry determines the existence of a small current component 

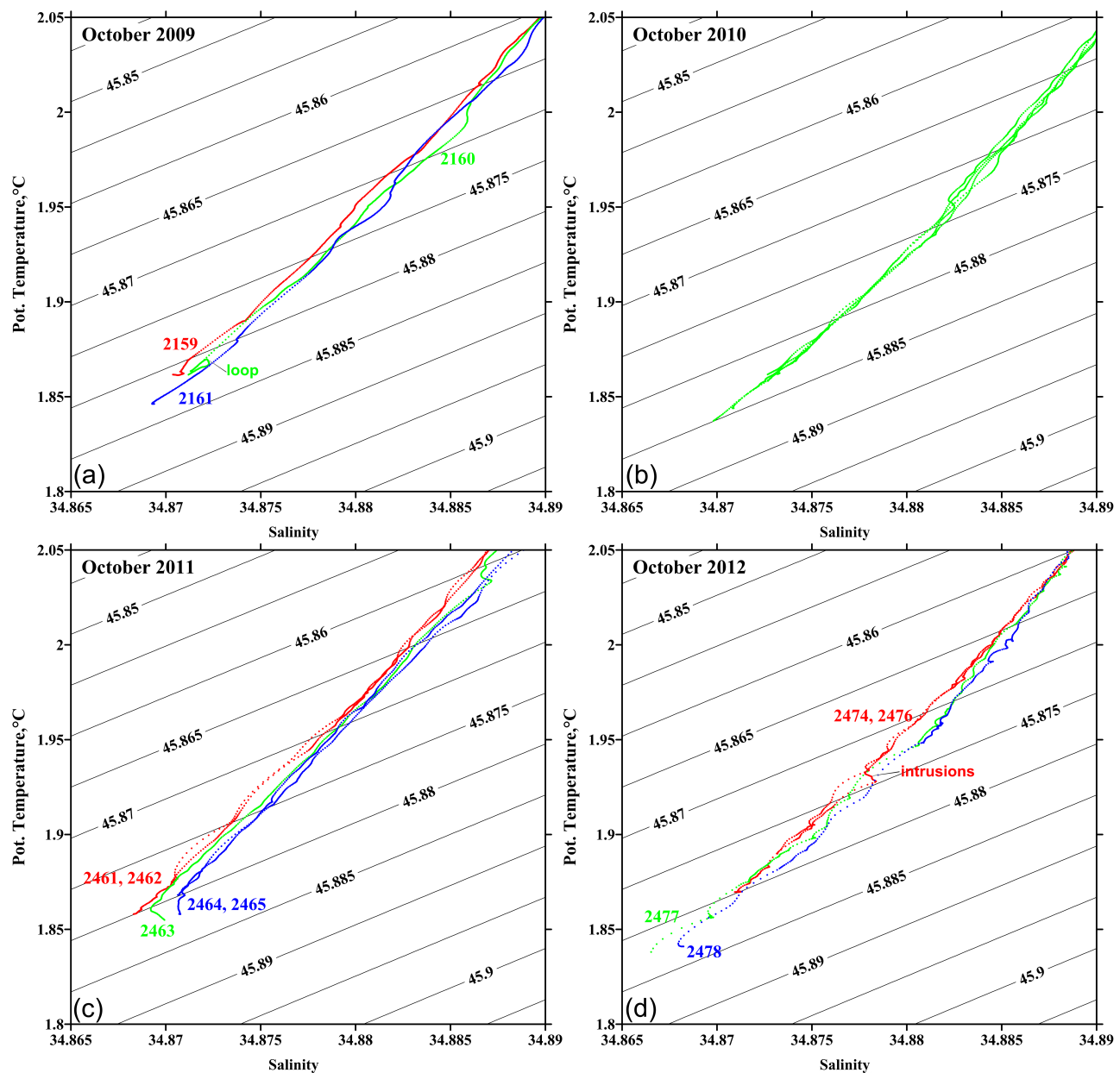

Fig. 9. $\Theta-S$ scatter plot of the bottom layer in the sections across the Kane Gap in October 2009 (a), October 2010 (b), October 2011 (c), and October 2012 (d). Isopleths of potential density $\sigma_{4}$ are also shown.

normal to the Kane Gap channel. Its value averaged over time at the bottom current meter was $1.6 \mathrm{~cm} \mathrm{~s}^{-1}$ strictly to the west and $1.3 \mathrm{~cm} \mathrm{~s}^{-1}$ to the west with a slight deviation to the south at the middle level. A similar calculation for the upper current meter resulted in a velocity of $1.6 \mathrm{~cm} \mathrm{~s}^{-1}$ strictly to the west. This is just a vector sum of year-long measurements of differently oriented currents that hardly has a physical basis.

The graphs of the meridional velocity components with daily averaging of the measurements for all three current meters (Fig. 11) demonstrate high correlation of these curves at sub-inertial frequencies. The currents of one direction with minor exceptions (either southerly or northerly) were observed simultaneously at all three levels. During the first six months of the mooring operation, a period of 180 days is clearly seen in the record (Fig. 11). However, the duration of the record did not allow us to resolve such long periods by the spectral analysis and only a 90 day period of sub-inertial motions was revealed in the first half of the time series and a 44 day period in the second half (Fig. 12). During the first three months (November-January) the meridional current compo- nents were positive (to the north). Then, the direction of the currents turned to the opposite and from February to the beginning of April the meridional velocity components were negative. In May 2011, the regime of the currents changed to predominant oscillations with a higher (sub-inertial) frequency. We estimate the average period of these fluctuations of shorter period at 44 days (Figs. 11, 12). We note that such effect was not seen in the zonal velocity component, which is related to the presence of four transport directions at the upper level unlike two at the middle and lower (Fig. 10).

The seasonal periodicity of current directions in the Kane Gap can be related to the seasonal variability of transport in the Romanche Fracture Zone found in Mercier and Speer (1998). Thierry et al. (2006) showed that the seasonal signal, which is observed in the Romanche Fracture Zone, was caused by the propagation of equatorial Rossby waves. This signal is thus likely to be confined to the equatorial band. However, an increase in the eastward velocity and transport could increase the amount of AABW in the Sierra Leone Basin that could partly discharge to the Gambia 


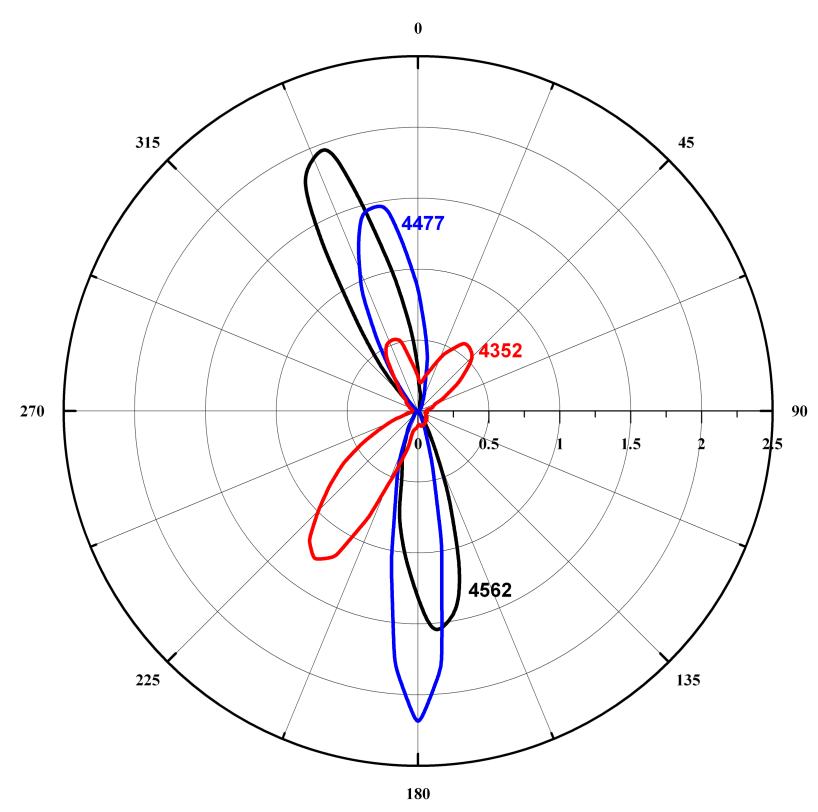

Fig. 10. Rose of the flow transports (percent per degree angle) over a period of the year based on the data of three current meters located at 4352,4477 , and $4562 \mathrm{~m}$.

Abyssal Plain through the Kane Gap, and the northerly flow in the passage could be a remote response to the seasonal signal in the Romanche Fracture Zone.

Figure 11 also shows the daily average temperature anomaly at all three levels. During the period when the currents had a northward meridional component, the temperature of the transported bottom water was slightly cooler than during the period of the southward transport. The greatest temperature anomalies (both positive and negative) up to $0.05^{\circ} \mathrm{C}$ were found at the middle and upper levels. The maximum temperature anomaly at the lower level was $0.025^{\circ} \mathrm{C}$. We also note that temperature at the bottom $(7 \mathrm{~m}$ above the bottom) varied in the range between 1.80 and $1.92{ }^{\circ} \mathrm{C}$. The daily average temperatures vary between 1.82 and $1.88^{\circ} \mathrm{C}$. These values exceed the minimum and maximum values measured by CTD instruments. We emphasize that the minimum temperature recorded by CTD measurements was $\Theta=$ $1.832^{\circ} \mathrm{C}$ in October 2012 (Fig. 6d).

The correlation of the southward (northward) transport with warming (cooling) of the bottom flow is most likely explained by the fact that bottom waters from the southern source (Romanche FZ) are cooler than those from the northwestern source (Vema FZ). This can also be seen in Fig. 2. Cooler bottom temperatures (relative to the temperatures at the sill) are found south of the Kane Gap rather than north of it. However, this statement can be true only for the vicinity of the Kane Gap. The other explanation of temperature dependence on the direction of the flow related to the Ekman friction can be as follows. The jet of the coldest water was displaced to the southwestern slope, which is explained by the Ekman frictional boundary layer (Northern Hemisphere) during the northward water flow (Speer and Zenk, 1993). This effect is seen on three of the four temperature sections (Fig. 6a, b, d) and not seen in Fig. 6c when the velocities were low. The densest (coldest) water flowing in the channel in the Northern Hemisphere is displaced to the left relative to its motion, i.e., to the southwestern slope when the flow is directed to the northwest, and to the northeast when the flow is directed to the southeast. Considering that the temperature measurements were made at the mooring, which was located closer to the southwestern slope, this effect will be manifested in the correlation between the direction of the current and temperature. However, this effect seems not likely because the temperature difference measured on the mooring during the year is approximately $0.1^{\circ} \mathrm{C}$, which is almost one order of magnitude greater than the horizontal temperature difference observed over the CTD sections.

In order to estimate the transport based on the data of moored current meters we plotted a section similar to the one for the station in May 2009 (Fig. 4). The transport calculation was made on the basis of three current meters in the layer from $4352 \mathrm{~m}$ to the bottom. It is seen in Figs. 5 and $6 \mathrm{a}$ that this depth is close to the isotherm $1.9^{\circ} \mathrm{C}$. The data were interpolated on a vertical grid with a step of $10 \mathrm{~m}$. Then, the calculation was similar to the calculations from the LADCP data over the sections.

The daily mean transport varied in this layer between $0.36 \mathrm{~Sv}$ to the south and $0.33 \mathrm{~Sv}$ to the north. The mean transport over the period when the current had southward direction was 0.20 and $0.23 \mathrm{~Sv}$ when the current was directed to the north. The total transport over the entire period of observations $(1 \mathrm{yr})$ was $0.014 \mathrm{~Sv}$ to the north. This transport is determined by the westerly drift component of the current mentioned above and seems to be quasi-constant. We emphasize that this total transport does not characterize the long-term transport through the Kane Gap (which is actually zero). In some sense, this small value is random depending on the specific point of the mooring location and line of the section across the Kane Gap.

It is interesting to compare the transports based on the LADCP data over sections in 2010 and 2011 with the transports based on the mooring data at the beginning and at the end of its operation. The transport over the period from 14:00 on 21 October 2010 to 14:00 LT on 22 October 2010 (beginning of the mooring operation) was $0.23 \mathrm{~Sv}$ to the north, and from 09:30 on 17 October 2011 to 09:30 on 18 October 2011 (last day) was $0.16 \mathrm{~Sv}$ to the south. The former is close to the estimate of the transport during the section occupied in the closest time ( $0.19 \mathrm{~Sv}$ to the north in 2010); the latter is strongly different $(0.02 \mathrm{~Sv}$ to the south in 2011). We note that the variation in the mean velocity over one day can reach $10 \mathrm{~cm} \mathrm{~s}^{-1}$, which is especially characteristic of the period of current reconstruction. This is clearly seen in Fig. 11a, in which every daily record is denoted with a dot. The indications of such a situation are observed over the section in 

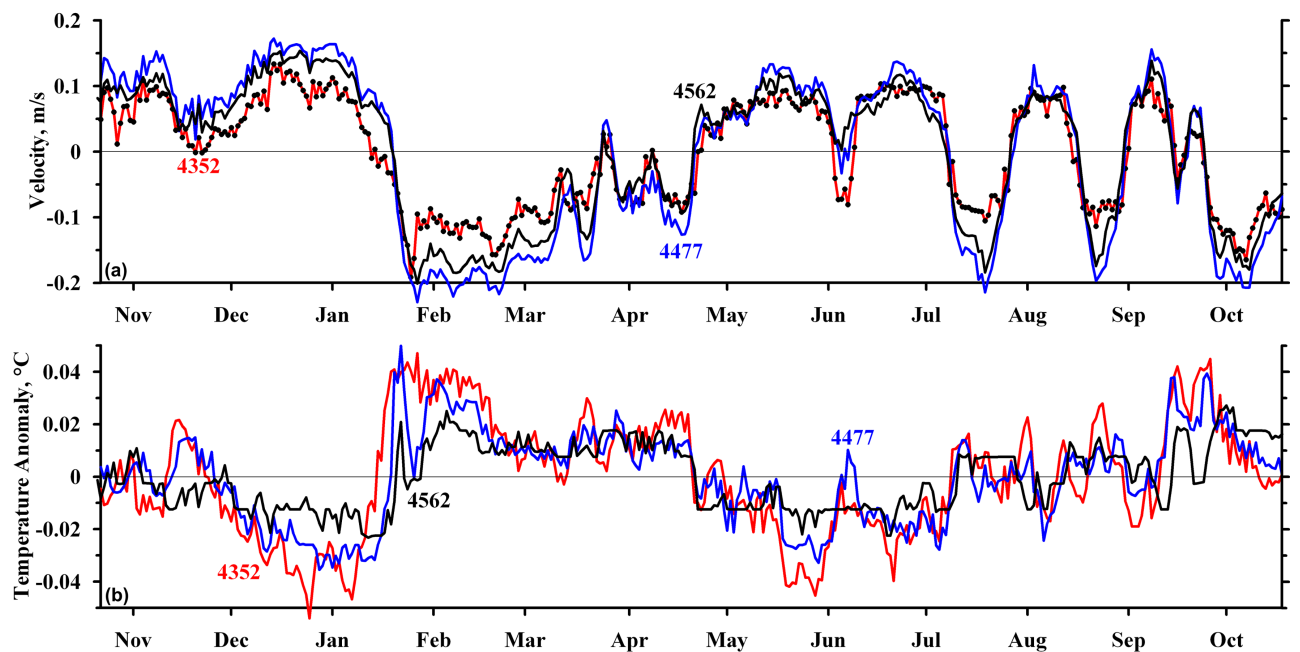

Fig. 11. Graphs of the current component along the main axis of the Kane Gap (north to south direction, positive to the north) (a) and temperature anomaly (b). The bottom axis shows the sequential months of measurements.
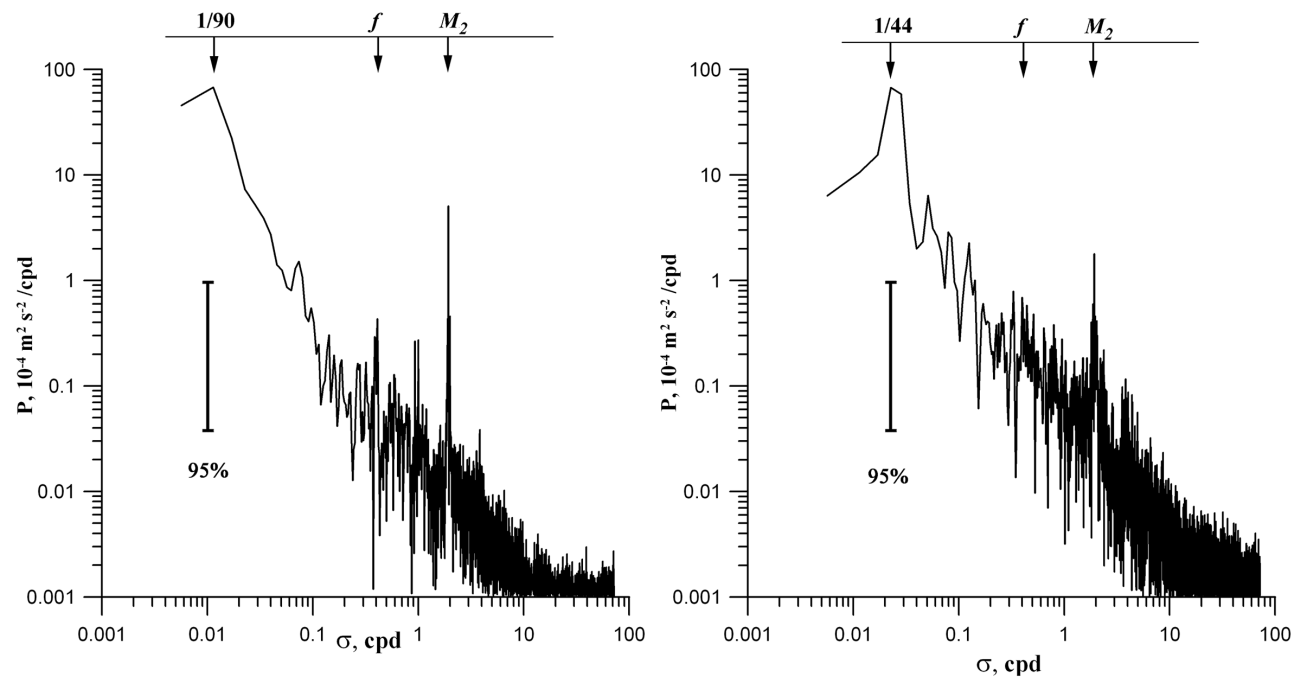

Fig. 12. Nearly raw spectra of kinetic energy from currents at $7 \mathrm{~m}$ above the bottom for the periods between November 2010 and May 2011 (left) and between May and October 2011 (right). The $95 \%$ confidence intervals are shown.

October 2011, which was occupied during the next day after recovery of the mooring. This is manifested first of all in the different directions of currents over the section.

We estimate the volume of bottom water transported through the Kane Gap during unidirectional flow and the square of the territory occupied by the water transported through the channel. The mean transport during the longest period of the permanent flow to the southeast (FebruaryApril 2011) was $0.20 \mathrm{~Sv}$. During this period, $1300 \mathrm{~km}^{3}$ of AABW was transported to the south of the Kane Gap. If we assume that the mean depth south of the Kane Gap is $4650 \mathrm{~m}$ and the layer of AABW is located below $4000-4200 \mathrm{~m}$, we estimate that the region filled with the bottom water transported from the north is limited by a distance of approxi- mately $50 \mathrm{~km}$ from the sill of the Kane Gap. This estimate is valid also to the north of the Kane Gap.

\section{Summary}

We analyzed the data of field measurements in the Kane Gap $\left(9^{\circ} \mathrm{N}\right)$, a deep passage between the Gambia Abyssal Plain and Sierra Leone Basin in the Atlantic Ocean, to study the low frequency flow of Antarctic Bottom Water through this channel. The measurements in the Kane Gap included five visits in 2009-2012 with CTD sections and a year-long record of bottom currents by three current meters. We found an alternating regime of flow, which changes direction several times during a year. The maximum 
daily average velocities in the southern direction reached $0.20 \mathrm{~m} \mathrm{~s}^{-1}$, while the maximum north-northwesterly currents were as high $0.15 \mathrm{~m} \mathrm{~s}^{-1}$. The transport of Antarctic Bottom Water $\left(<1.9^{\circ} \mathrm{C}\right)$ varied approximately by $\pm 0.35 \mathrm{~Sv}$ based on the LADCP and moored measurements, while the longterm mean is almost zero ( $0.014 \mathrm{~Sv}$ to the north). The AABW transported through the Kane Gap to the north and south will not propagate over a distance exceeding $50 \mathrm{~km}$.

Acknowledgements. The mooring with current meters was supplied by the Royal Netherlands Institute for Sea Research. It was financially supported in part by the Netherlands Organization for Scientific Research (NWO) in the Russian-Dutch exchange program. The work was supported by the Russian Foundation for Basic Research (grants 09-08-10000-k, 12-05-00277, 11-08-00076) and the NWO-RFBR program (project No. 047.017.2006.003).

Edited by: M. Hoppema

\section{References}

Fischer, J., Rhein, M., Schott, F., and Stramma, L.: Deep water masses and transports in the Vema Fracture Zone, Deep-Sea Res. I, 43, 1067-1074, 1996.

Hall, M. M., McCartney, M. S., and Whitehead, J. A.: Antarctic Bottom Water flux in the Equatorial Western Atlantic, J. Phys. Oceanogr., 27, 1903-1926, 1997.

Hobart, M. A., Bunce, E. T., and Sclater, J. G.: Bottom water flow through the Kane Gap, Sierra Leone Rise, Atlantic Ocean, J. Geophys. Res., 80, 5083-5088, 1975.

Hogg, N. G.: Quantification of the deep circulation, in: Ocean Circulation and Climate, edited by: Siedler, G., Church, J., and Gould, J., Academic Press, San Diego, 259-270, 2001.

Hogg, N.G., Siedler G., and Zenk W.: Circulation and variability at the southern boundary of the Brazil Basin, J. Phys. Oceanogr., 29, 145-157, 1999.

Mantyla, A. W. and Reid, J. L.: Abyssal characteristics of the World Ocean waters. Deep-Sea Res., 30, 805-833 1983.

McCartney, M. S., Bennet, S. L., and Woodgate-Jones, M. E.: Eastward flow through the Mid-Atlantic ridge at $11^{\circ} \mathrm{N}$ and its influence on the abyss of the Eastern basin, J. Phys. Oceanogr., 21, 1089-1121, 1991.
Mercier, H. and Morin, P.: Hydrography of the Romanche and Chain Fracture Zones, J. Geophys. Res., 102, 10373-10389, 1997.

Mercier, H. and Speer, K. G.: Transport of bottom water in the Romanche Fracture Zone and the Chain Fracture Zone, J. Phys. Oceanogr., 28, 779-790, 1998.

Morozov, E. G, Demidov, A., Tarakanov, R., and Zenk, W.: Abyssal Channels in the Atlantic Ocean: Water Structure and Flows, Springer, 2010a.

Morozov, E. G., Tarakanov, R. Y., and Demidov, A. N., Transport of bottom waters in the Kane Gap., Doklady Earth Sciences, 433, 1062-1066, 2010b.

Morozov, E. G., Tarakanov, R., Y., Gritsenko, A. M., Demidova, T. A., and Makarenko, N. I.: Measurements of currents in abyssal channels during cruise 32 of the R/V Akademik Ioffe and cruise 34 of the R/V Akademik Sergey Vavilov, Oceanology, 52, 721723, 2012.

Smith, W. H. F. and Sandwell, D. T.: Global sea floor topography from satellite altimetry and ship depth soundings, Science, 277, 1956-1962, http://topex.ucsd.edu/cgi-bin/get_data.cgi, 1997.

Speer, K. G. and Zenk, W.: The flow of Antarctic Bottom water into the Brazil Basin, J. Phys. Oceanogr., 23, 2667-2682, 1993.

Rhein, M., Stramma L., and Krahmann G.: The spreading of Antarctic Bottom Water in the tropical Atlantic, Deep-Sea Res. I, 45, 507-527, 1998.

Tarakanov, R. Y., Makarenko, N. I., and Morozov, E. G.: Antarctic bottom water flow in the western part of Romanche F. Z. based on measurements in October 2011, Oceanology, 53, 580-592, 2013.

Thierry, V., Mercier, H., and Treguier, A. M.: Seasonal fluctuations in the deep central equatorial Atlantic Ocean: a data-model comparison, Ocean Dynam., 581-593, doi:10.1007/s10236-0050045-y, 2006.

van Aken, H. M.: The hydrography of the mid-latitude northeast Atlantic Ocean, Pt. I, 47, 757-788, 2000.

Visbeck, M.: Deep velocity profiling using lowered acoustic doppler current profiler: bottom track and inverse solution, J. Atmos. Oceanic Technol., 19, 794-807, 2002.

WOD09: World Ocean Data Base http://www.nodc.noaa.gov/OC5/ SELECT/dbsearch/dbsearch.html, 2009.

Wüst, G.: Schichtung und Zirkulation des Atlantischen Ozeans, Das Bodenwasser und die Stratosphäre, in: Wissenschaftliche Ergebnisse, Deutsche Atlantische Expedition auf dem Forschungs und Vermessungsschiff Meteor“" 1925-1927, edited by: Defant, A., 6 Walter de Gruyter \& Co, Berlin, 411 pp., 1936. 